\title{
Microstructure and Mechanical Behavior of $\mathrm{Ag}_{\mathrm{C}} \mathrm{NP} / 2024 \mathrm{Al}$ Composites
}

\author{
C. Carreño-Gallardo ${ }^{*}{ }^{* *}$, I. Estrada-Guel ${ }^{*},{ }^{* *}$, Neri M. A. , M. Romero-Romo ${ }^{* *}$, C. López-Meléndez ${ }^{*}$
} and R. Martínez-Sánchez ${ }^{*}$.

*Centro de Investigación en Materiales Avanzados (CIMAV), Miguel de Cervantes \#. 120, C.P. 31109. Chihuahua, México.

** Universidad Autónoma Metropolitana, Departamento de Materiales, Av. San Pablo \# 180, Col. Reynosa-Tamaulipas, CP 02200. D. F. México.

Many aluminum alloys are based on precipitation strengthening, so by heat treatment aluminum alloys develop the optimum balance of mechanical properties. Additionally, aluminum alloys can be reinforced by second phase dispersion. Some aluminum alloys can be strengthened by second phase dispersion and by precipitation (aging).

The present work was aimed to study the effect of age treatment on an AA2024 Aluminum alloy $\left(\mathrm{Al}_{2024}\right)$ and $\mathrm{Al}_{2024}$ reinforced with carbon-coated silver Nanoparticles $\left(\mathrm{Ag} \mathrm{g}_{\mathrm{C} P}\right)$. Microstructural and mechanical characterization is reported as a function of age treatment and $\mathrm{Ag}_{\mathrm{C}} \mathrm{NP}$ concentration.

The raw material used in this study was $\mathrm{Al}_{2024}$ commercial alloy and silver nanoparticles obtained by plasma discharge. The chemical composition of $\mathrm{Al}_{2024}$ is shown in Table 1 .

The $\mathrm{Al}_{2024}$ powder was produced by machining a solid extruded bar. The machined metal shavings were mixed with $\mathrm{Ag}_{\mathrm{C}} \mathrm{NP}$ in different concentrations $\left(0.00,1.50,2.50\right.$ and $3.0 \mathrm{wt} . \% \mathrm{Ag}_{\mathrm{C} P} \mathrm{NP}$. Mixtures were mechanically milled in a high-energy horizontal mill (ZOZ CM01 Simoloyer) under argon atmosphere. Milled products were hot extruded to obtain a solid bar. Solution treatment at $495^{\circ} \mathrm{C}$ for $1 \mathrm{~h}$ and water quenched followed by aging treatment at $190^{\circ} \mathrm{C}$ for $2 \mathrm{~h}$ was applied to all solid samples.

The age hardening responses of composites and unreinforced matrix alloy were characterized using Vickers microhardness measurement. Fig.1. shows the effect of $\operatorname{Ag}_{\mathrm{C}} \mathrm{NP}$ and heat treatment on mechanical properties. Evident difference after aging is observed, as well as, an important effect of concentration of $\mathrm{Ag}_{\mathrm{C}} \mathrm{NP}$. From 0.0, 1.5, 2.5 and 3.0 wt. \% of $\mathrm{Ag}_{\mathrm{C}} \mathrm{NP}$ the increment observed was about of $29 \%$ compared with $\mathrm{Al}_{2024}$ T6. Higher $\mathrm{Ag}_{\mathrm{C}} \mathrm{NP}$ concentration has a negative effect on mechanical properties. However, this value is high than that reported for $\mathrm{Al}_{2024}-\mathrm{T} 6$ [1].

The foils of the composites and matrix alloy for TEM analysis were jet polished with $\mathrm{HNO}_{3}$ and methanol at $-25^{\circ} \mathrm{C}$. Fig. 2 . shows the precipitate morphology in the composite after aging at $190^{\circ} \mathrm{C}$ for $2 \mathrm{~h}$, the tiny needle shaped precipitates are observed in the matrix. Spherical nanoparticles corresponding to $\mathrm{Ag}_{\mathrm{C}} \mathrm{NP}$ homogeneously distributed in the matrix are observed. There are some dislocations in the composite interacting with $\mathrm{Ag}_{\mathrm{C}} \mathrm{NP}$ and precipitates $\theta^{\prime}$ distributed homogeneously were observed in the matrix

\section{References}

[1] MatWeb, Online Materials Property Data Sheet. http://www.matweb.com. 
TABLE 1. Composition of the $\mathrm{Al}_{2024}$ used (wt.\%) in this work.

\begin{tabular}{ccccccc}
\hline Al & Cr & Cu & Fe & Mg & Mn & Si \\
Bal. & 0.038 & 4.004 & 0.246 & 0.876 & 0.673 & 0.128 \\
\hline
\end{tabular}

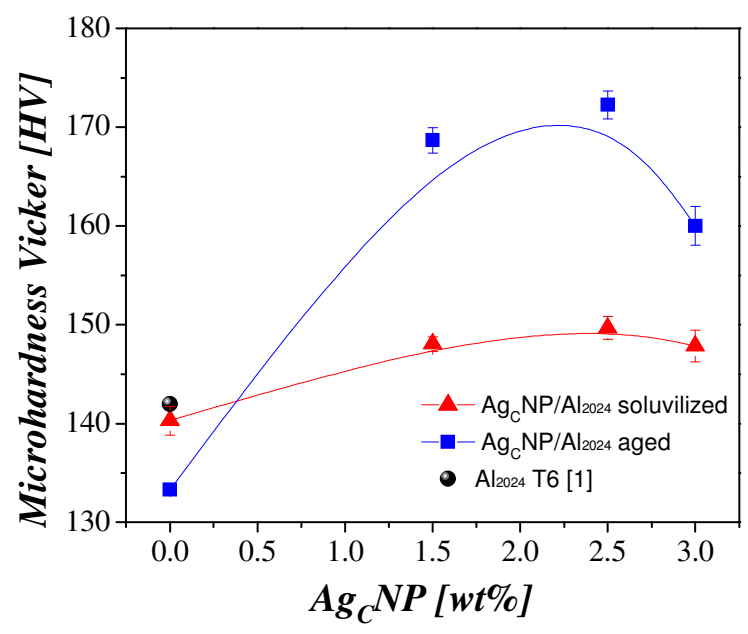

FIG. 1. Variation of hardness as a function of $\mathrm{Ag}_{\mathrm{C}} \mathrm{NP}$ content.

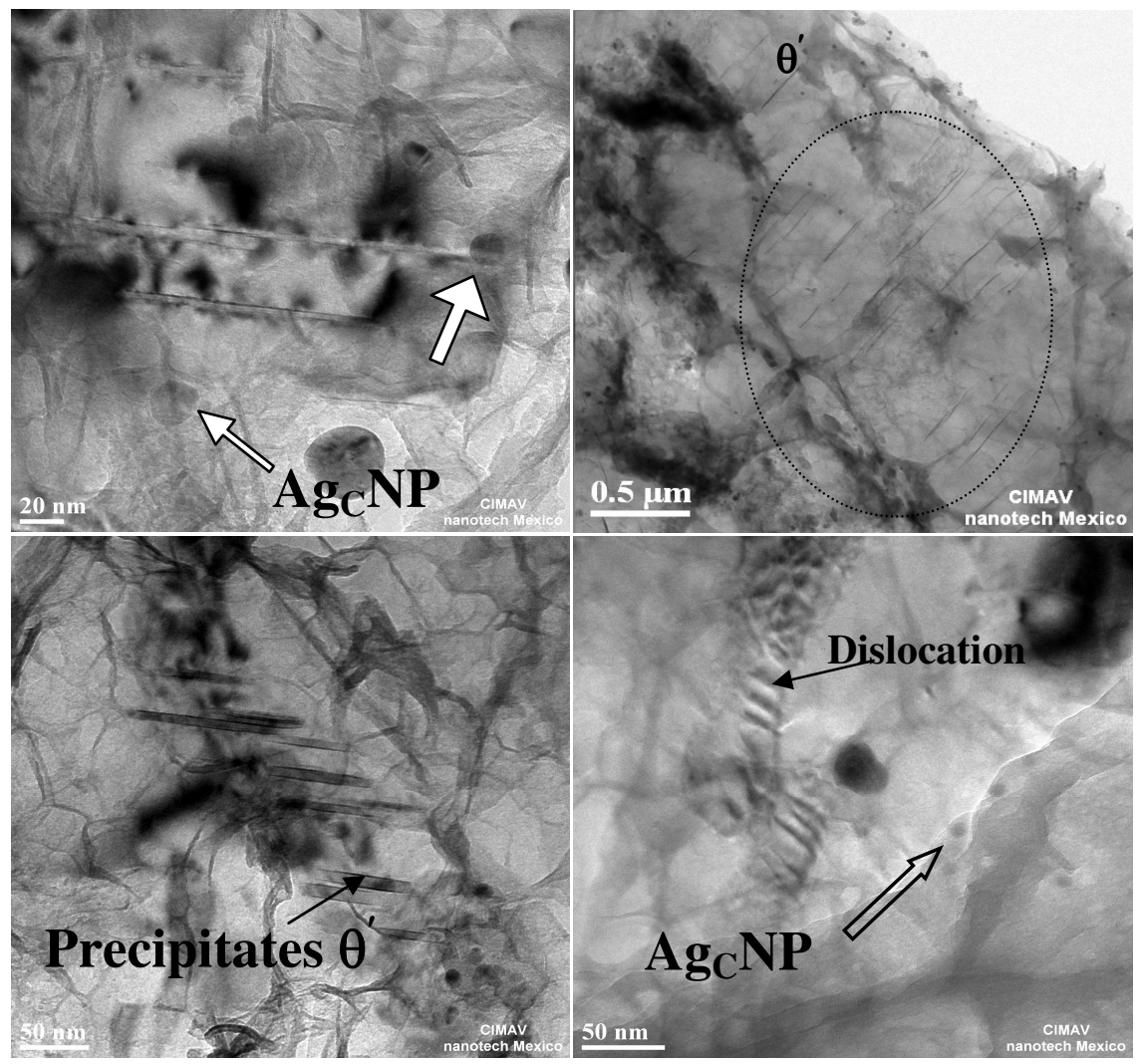

FIG. 2. Precipitate morphology in $\mathrm{Ag}_{\mathrm{C}} \mathrm{NP} / 2024 \mathrm{Al}$ composite aged at $190^{\circ} \mathrm{C}$ 